\title{
KINETIKA DEGRADASI SELULOSA ASETAT DARI SABUT PINANG
}

\author{
Intan Syahbanu ${ }^{1 *}$, Annisa Anugraini ${ }^{1}$, Husna Amalya Melati ${ }^{2}$ \\ 1 Jurusan Kimia, Fakultas MIPA, Universitas Tanjungpura, Kalimantan Barat, Indonesia \\ 1 Jurusan Pendidikan Kimia, Fakultas KIP, Universitas Tanjungpura, Kalimantan Barat, \\ Indonesia
}

${ }^{*}$ Corresponding author:intan.syahbanu@chemistry.untan.ac.id

\begin{tabular}{l}
\hline ARTICLE INFO \\
Article history: \\
Received 21 May \\
2018 \\
Accepted 28 May \\
2018 \\
Available online \\
26 June 2018 \\
Keywords: \\
Cellulose acetate \\
Sonication \\
Kinetics \\
Degradation \\
\end{tabular}

\begin{abstract}
Cellulose Acetate is a material with wide range in applications. Cellulose acetate may obtain from natural resources, such as areca fiber. Polymers should have uniform molecular weight for the applications and could be modify by ultrasonic waves. Ultrasonic treatment on polymer entangled with polymer degradation. In this research, degradation kinetics of cellulose acetate in acetone had been studied. Analysis was performed by determination of intrinsic viscosity in polymer solution system. Intrinsic viscosity was successfully obtained by fitting data using Huggins equation, indicate molecular interaction in polymer solution should not be neglected. Increasing in sonication time reducing the intrinsic viscosities as well as molecular size in solutions. Degradation rate constant and reaction order were obtained $5,975 \times 10^{-3}$ (g.mL$\left.{ }^{1}\right)^{0,1} \cdot \mathrm{min}^{-1}$ and 1,0616, respectively. Kinetics model was successful to determine the degradation rates of cellulose acetate on acetone by correlation coefficient $\left(R^{2}\right)$ at 0,966 .
\end{abstract}

(C) 2018 IJoPAC. All rights reserved

\section{Pendahuluan}

Selulosa asetat (SA) merupakan ester organik selulosa yang berupa padatan putih, tidak berbau dan tidak berasa serta merupakan ester yang paling penting yang berasal dari asam organik[1]. Selulosa asetat dapat disintesis dari bahan alam. Selulosa asetat dapat disintesis dari serat daun nanas, bahan baku koran[2], limbah kapas ${ }^{[3]}$, jerami ${ }^{[4]}$, dan pulp kenaf[5]. Salah satu sumber selulosa yang dapat dimodifikasi menjadi selulosa asetat adalah sabut pinang[6]. Selulosa asetat yang dihasilkan tergolong selulosa diasetat dengan nilai derajat subtitusi berkisar pada 2,8-2,9. Selulosa asetat memiliki nilai komersil yang baik dan telah diaplikasikan secara luas sebagai filter, plastik ramah lingkungan, dan dalam industri kertas dan tekstil.

Terkait dengan aplikasinya, diperlukan material dengan distribusi massa molekul yang sempit, sehingga ukurannya lebih seragam. Modifikasi material ini dapat melibatkan proses degradasi polimer. Beberapa teknik telah diterapkan dalam modifikasi material, salah satunya dengan teknik sonikasi. Sonikasi termasuk metode yang cepat dan mudah, tidak membutuhkan banyak penambahan bahan kimia, tidak mengakibatkan perubahan yang signifikan pada struktur kimia partikel dan senyawa bahan baku yang digunakan[7].

Penggunaan sonikasi dapat menyebabkan perubahan massa molekul rata-rata viskositas (Mv) dengan adanya reduksi viskositas akibat pemberian gelombang ultrasonik ${ }^{[8]}$. Beberapa penelitian sebelumnya menyebutkan bahwa terjadinya reduksi viskositas pada larutan polimer yang diberi gelombang ultrasonik. Hal ini dinyatakan bahwa hubungan larutan polimer yang 
diberi gelombang ultrasonik pada energi yang tinggi dapat menghasilkan reduksi viskositas yang bersifat permanen[12].

Pada penelitian ini dilakukan studi kinetika degradasi terhadap selulosa asetat yang telah disintesis dari sabut pinang. Melalui studi ini akan dipelajari pengaruh sonikasi terhadap viskositas larutan polimer dan kinetika degradasi selulosa asetat dalam rentang waktu 0,15,30,60 dan 120 menit, dan dimodelkan dalam persamaan hingga diperoleh nilai konstanta laju reaksi dan orde reaksi.

\section{Bahan dan Metode}

Studi kinetika degradasi pada penelitian ini dilakukan pada selulosa asetat asetat yang telah disintesis dari sabut pinang pada penelitian sebelumnya[6].Selulosa asetat diberi perlakuan menggunakan ultrasonic batch (Branson) dengan frekuensi $42 \mathrm{kHz}$ dan daya 30 Watt. Studi kinetika degradasi dilakukan dengan cara viskometri, melalui penentuan nilai viskositas intrinsik dari selulosa asetat dalam pelarut aseton yang disonikasi dengan variasi $0,15,30,60$ dan 120 menit. Pengolahan data dilakukan menggunakan Microsoft Office Excell 2007 dan Origin 8.

\section{Penentuan viskositas intrinsik [ๆ]}

Viskositas intrinsik [ $\eta$ ] dilakukan dengan asumsi larutan polimer yang diencerkan tak hingga $(C \rightarrow 0)$. Nilai viskositas intrinsik diturunkan dari dari nilai viskositas relatif dan viskositas spesifik. Viskositas relatif $\left(\eta_{\text {rel }}\right)$ dapat didefinisikan sebagai rasio viskositas larutan (1) dengan viskositas pelarut murni ( $\left.\eta_{0}\right)$ (persamaan 1) dan viskositas spesifik $\left(\eta_{\mathrm{sp}}\right)$ didefinisikan pada persamaan (2). Viskositas relatif bervariasi dengan konsentrasi, sebagai berikut[13]:

$$
\begin{aligned}
& \eta_{\text {rel }}=\eta / \eta_{o}=1+\eta C+k \eta^{2} C^{2}+\ldots \text { dan seterusnya } \\
& \eta_{\text {sp }}=\eta-\eta_{o} / \eta_{o}
\end{aligned}
$$

Dari persamaan (1), untuk konsentrasi yang rendah $(\leq 1 \%)$, persamaan diatas $\mathrm{c}^{2}$ dapat diabaikan dan diperoleh persamaan Huggins yaitu :

$$
\eta_{\mathrm{sp}} / \mathrm{C}=\left(\eta-\eta_{\mathrm{o}}\right) / \eta_{\mathrm{o}} \mathrm{C}=\eta+\mathrm{k} \eta^{2} \mathrm{C}
$$

dengan $\eta_{\mathrm{sp}} / \mathrm{C}$ juga disebut sebagai viskositas tereduksi. Viskositas intrinsik ditentukan dengan persamaan limit berikut :

$$
[\eta]=\lim _{c \rightarrow 0}\left[\left(\eta-\eta_{0}\right) / \eta_{0} C\right]
$$

Nilai [n] dapat ditentukan dengan memplotkan $\left(\left(\eta-\eta_{0}\right) / \eta_{0} C\right)$ dari fungsi $C$.

Pada larutan yang sangat encer, dapat interaksi antara polimer dan pelarut dapat diabaikan, sehingga persamaan Hunggins dapat disederhanakan menjadi persamaan (5) berikut[10]:

$$
\eta_{\text {rel }}=1+[\eta] C
$$

\section{Kinetika degradasi polimer}

Laju degradasi dari suatu polimer dapat digambarkan seperti laju reaksi orde ke-n yang bergantung pada konsentrasi dari polimer $\left([\mathrm{M}]_{\mathrm{t}}\right.$ ). Persamaan (6) menunjukkan persamaan laju degradasi polimer[9], dengan $\mathrm{t}$ adalah waktu reaksi, $\mathrm{n}$ adalah orde reaksi dan $\mathrm{k}^{\prime}$ adalah konstanta laju reaksi. 


$$
\frac{d[M]_{t}}{d t}=k^{\prime}[M]_{t}^{n}
$$

Melalui proses integrasi persamaan (6), dengan menerapkan pada keadaan $t=0,[M]_{t}=[M]_{0}$, dengan $[\mathrm{M}]_{0}$ adalah total konsentrasi molar polimer, maka persamaan (6) dapat ditulis dalam persamaan (7) :

$$
[\mathrm{M}]_{\mathrm{t}}^{1-\mathrm{n}}-[\mathrm{M}]_{0}^{1-\mathrm{n}}=(1-\mathrm{n}) \mathrm{k}^{\prime} \mathrm{t}
$$

Nilai total konsentrasi molar polimer akan meningkat selama proses degradasi, sehingga nilainya akan sebanding dengan konsentrasi larutan dan massa molekul rata-rata jumlah $\left(\mathrm{M}_{\mathrm{n}}\right)$ polimer (Persamaan 8).

$$
[M]=\frac{c}{M_{n}}
$$

Massa molekul relatif polimer juga dapat diperoleh melalui metode viskometri, yang disebut dengan massa molekul rata-rata viskositas $\left(\mathrm{M}_{\mathrm{v}}\right)$ dengan menggunakan persamaan MarkHouwink Sakurada (9) ${ }^{[13]}$ :

$$
[\mathrm{\eta}]=\mathrm{KM}_{\mathrm{v}}{ }^{\alpha}
$$

Dimana $\mathrm{K}$ dan $\alpha$ adalah konstanta. Untuk selulosa asetat dalam pelarut aseton, nilai $\mathrm{K}$ sebesar 0,00133 dan $\alpha$ sebesar 0,616 . Hubungan antara $M_{n}$ dan $M_{\vee}$ dapat dituliskan dalam persamaan $(10)^{[10]}$.

$$
M_{v}=\left[(1+\alpha) \int_{0}^{\infty} e^{-x} x^{\alpha} d x\right]^{1 / \alpha} M_{n} \equiv[1+\alpha] \Gamma(1+\alpha)^{1 / \alpha} M_{n}
$$

Persamaan (7) dan (10) dihubungkan melalui persamaan (11), sebagai berikut :

$$
[\eta]_{t}^{\frac{n-1}{\alpha}}-[\eta]_{0}^{\frac{n-1}{\alpha}}=(1-n) k^{\prime \prime} t
$$

Dengan k" didefinisikan dalam persamaan (12):

$$
k^{\prime \prime}=\frac{k^{\prime}}{\left(K[(1+\alpha) \Gamma(1+\alpha)] C^{\alpha f^{\prime}}\right)^{\frac{1-\bar{n}}{\alpha}}}
$$

\section{Hasil dan Pembahasan}

\subsection{Penentuan Nilai Viskositas Intrinsik}

Penentuan nilai viskositas intrinsik polimer dilakukan pada larutan polimer tanpa perlakukan sonikasi dan diberi perlakukan sonikasi selama 15 menit, 30 menit, 60 menit, dan 120 menit. Penentuan nilai viskositas intrinsik ini dilakukan dengan 2 persamaan, yaitu 
melakukan plot data menggunakan persamaan Huggins (persamaan 3) dan persamaan (5). Hasil plot data disajikan pada Gambar 1 dan 2 dan Tabel 1 sebagai berikut :

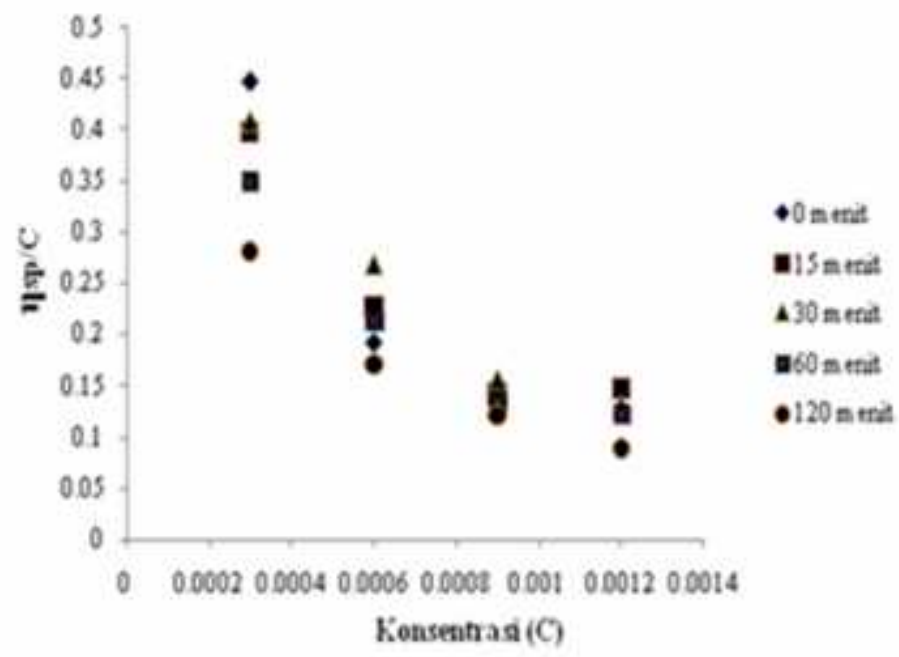

Gambar 1 Plot antara viskositas tereduksi terhadap konsentrasi

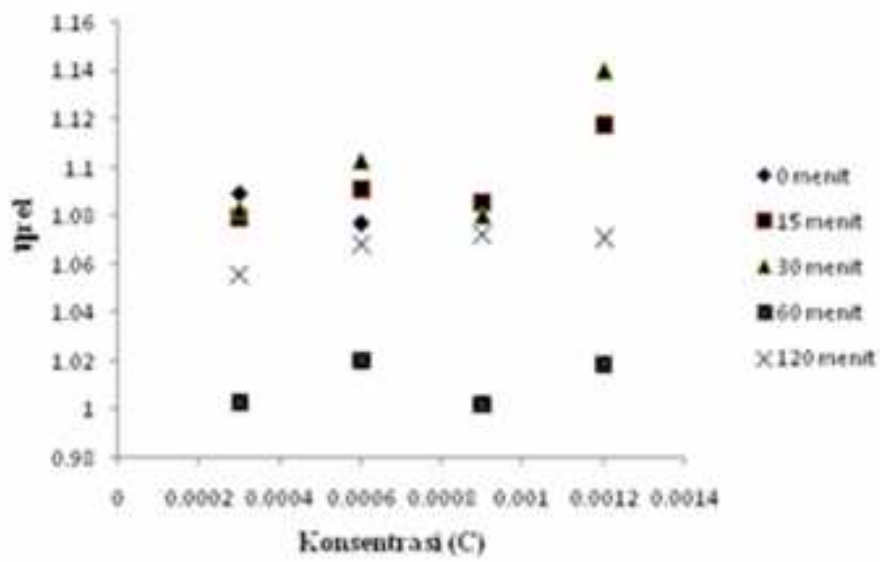

Gambar 2 Plot antara viskositas relatif terhadap konsentrasi

Tabel 1 Perbandingan nilai viskositas intrinsik yang diperoleh dari kedua model

\begin{tabular}{clccc}
\hline \multirow{2}{*}{$\begin{array}{c}\text { Waktu sonikasi } \\
\text { (menit) }\end{array}$} & \multicolumn{2}{c}{$\begin{array}{c}\text { Persamaan (3): } \\
\eta_{\mathrm{sp}} / \mathrm{C}=\eta+\mathrm{k} \eta^{2} \mathrm{C}\end{array}$} & \multicolumn{2}{c}{$\begin{array}{c}\text { Persamaan (5): } \\
\eta_{\text {rel }}=1+[\eta] \mathrm{C}\end{array}$} \\
\cline { 2 - 5 } & {$[\eta]$} & $\mathrm{R}^{2}$ & {$[\eta]$} & $\mathrm{R}^{2}$ \\
\hline 0 & 0,565 & 0,871 & - & 0,120 \\
15 & 0,511 & 0,963 & - & 0,288 \\
30 & 0,531 & 0,996 & - & 0,010 \\
60 & 0,446 & 0,978 & - & 0,001 \\
120 & 0,350 & 0,995 & 1,049 & 0,912 \\
\hline
\end{tabular}


Persamaan (3) merupakan Persamaan Huggins yang memperhitungkan pengaruh interaksi antara pelarut dan zat terlarut. Untuk persamaan (5), digunakan asumsi bahwa larutan polimer sangat encer, sehingga tidak ada interaksi molekuler. Hasil perhitungan menunjukkan persamaan (3) berhasil diterapkan untuk menghitung viskositas intrinsik dari larutan polimer, dengan nilai koefisian korelasi $\left(\mathrm{R}^{2}\right)$ berkisar dari 0,871 hingga 0,996, sedangkan persamaan (5) tidak berhasil karena diperoleh nilai koefisien korelasi $\left(\mathrm{R}^{2}\right)$ yang sangat kecil, sehingga nilai viskositas intrinsik tidak dapat ditentukan untuk polimer dengan waktu sonikasi 0 hingga 60 menit. Hal ini menunjukkan bahwa interaksi molekuler di dalam sistem larutan polimer adalah faktor penting dan tidak boleh diabaikan pada polimer karena rantai molekulnya yang panjang[10].

Rantai yang panjang pada polimer menyebabkan orientasi struktur yang kompleks di dalam larutan. Pada waktu sonikasi 120 menit, fitting dengan persamaan (5) menunjukkan koefisien korelasi $\left(\mathrm{R}^{2}\right)$ pada 0,912 . Hal ini dikarenakan dengan waktu sonikasi yang lama, polimer telah mengalami degradasi sehingga terjadi penurunan panjang rantai, akibatnya larutan menjadi lebih encer, sehingga persamaan (5) dapat diterapkan hanya pada larutan polimer setelah sonikasi selama 120 menit. Penurunan panjang rantai di menit ke 120 didukung oleh data pada penelitian sebelumnya, dimana penurunan massa molekul $\left(\mathrm{M}_{\mathrm{v}}\right)$ terjadi secara signifikan pada setelah proses sonikasi selama 120 menit[6]. Penentuan kinetika degradasi selulosa asetat selanjutnya dipelajari dengan menggunakan data viskositas intrinsik hasil analisis dengan persamaan (3).

\subsection{Studi Kinetika Degradasi Selulosa Asetat}

Degradasi polimer akibat gelombang ultrasonik disebabkan adanya kavitasi dalam sistem larutan polimer yang menyimpan potensi energi yang selanjutnya dapat memutus rantai polimer[11]. Laju degradasi polimer dapat dipelajari melalui pendekatan perhitungan nilai

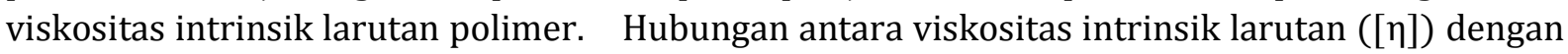
waktu sonikasi disajikan pada Gambar 3.

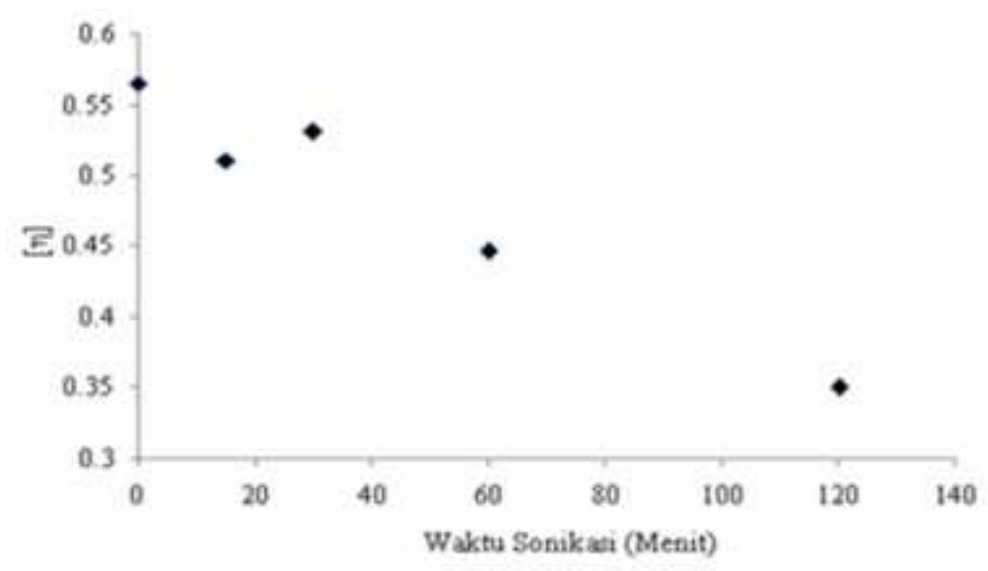

Gambar 3. Hubungan antara viskositas instrinsik dengan waktu sonikasi

Gambar 3 menunjukkan dengan bertambahnya waktu sonikasi, nilai viskositas intrinsik polimer juga menurun. Hal ini mengindikasikan bahwa degradasi polimer terjadi selama proses sonikasi.

Studi kinetika degradasi dilakukan dengan melakukan fitting data menggunakan persamaan (11). Nilai konstanta Mark-Houwink-Sakurada yang digunakan adalah $\mathrm{K}=0,00133$ dan $\alpha=0,616$ 
untuk larutan selulosa asetat dalam pelarut aseton[14]. Gambar 4 menunjukkan hasil plot grafik pada penentuan konstanta laju dan orde reaksi degradasi selulosa asetat.

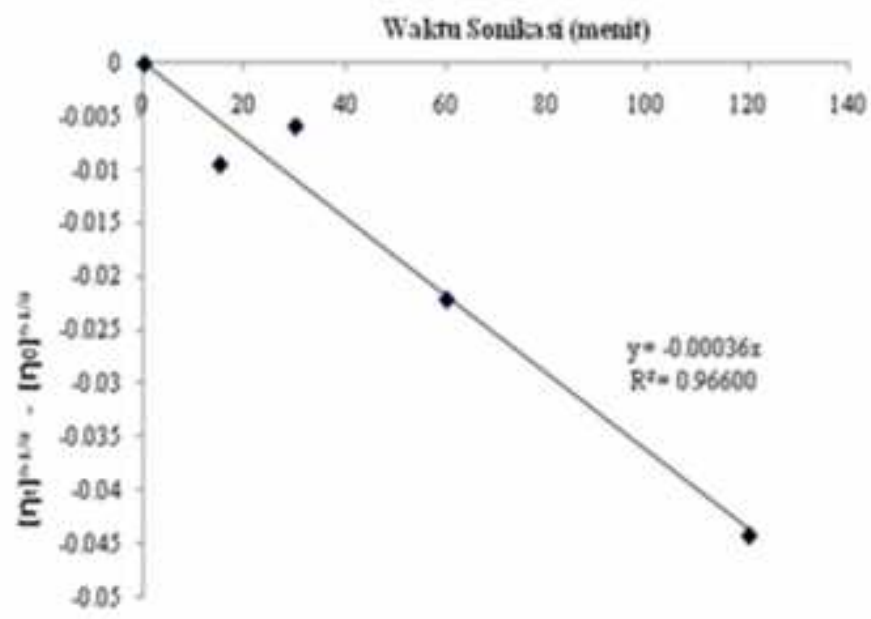

Gambar 4 Plot grafik penentuan laju degradasi selulosa asetat sesuai persamaan (11)

Plot grafik pada Gambar 4 digunakan untuk menghitung konstanta laju reaksi degradasi dan

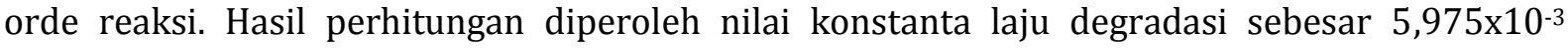
(g.mL - $\left.^{-1}\right)^{0,1}$.menit ${ }^{-1}$, dan orde reaksi 1,0616. Pada proses degradasi mekanik umumnya ditemukan nilai orde reaksi yang bernilai negatif[9][10], yang maknanya produk hasil degradasi yang terbentuk menghambat terjadinya reaksi degradasi lebih lanjut. Pada penelitian ini diperoleh nilai orde reaksi yang positif. Hal ini dikarenakan frekuensi gelombang ultrasonik yang digunakan tergolong rendah $(42 \mathrm{kHz})$, sehingga pengaruhnya terhadap degradasi selulosa asetat sangat lambat, dan produk hasil degradasi yang terbentuk belum banyak hingga menit ke 120. Hal ini didukung data dari penelitian sebelumnya menunjukkan bahwa sonikasi berpengaruh signifikan terhadap penurunan $\mathrm{M}_{\mathrm{v}}$ setelah proses selama 120 menit[6]. Oleh karena itu, proses degradasi tidak terhambat dan masih terus berlanjut. Plot grafik pada Gambar 4 menunjukkan nilai koefisien korelasi $\left(R^{2}\right)$ sebesar 0,966, sehingga dapat disimpulkan persamaan (11) sesuai digunakan untuk memodelkan kinetika degradasi selulosa asetat dalam pelarut aseton.

\section{Kesimpulan}

Kinetika degradasi selulosa asetat dari serat alam sabut pinang telah berhasil dipelajari dengan penentuan nilai viskositas intrinsik dari larutan polimer. Hasil analisis menunjukkan bahwa dalam penentuan nilai viskositas intrinsik, interaksi molekuler dalam sistem larutan

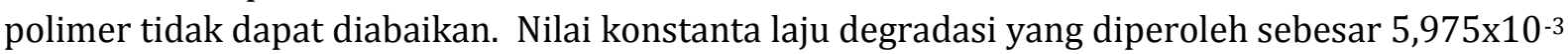
$\left(\text { g.mL }{ }^{-1}\right)^{0,1}$.menit-1 dan orde reaksi sebesar 1,0616. Berdasarkan hasil analisis, persamaan (11) menunjukkan koefisien korelasi sebesai 0,966 sehingga persamaan tersebut sesuai diterapkan dalam studi degradasi selulosa asetat.

\section{Ucapan terima kasih}

Ucapan terimakasih disampaikan kepada Kemenristek DIKTI atas dukungan dana melalui program PEKERTI. Demikian juga terimakasih disampaikan kepada Universitas Tanjungpura atas dukungan dan fasilitas yang diberikan untuk program PEKERTI tersebut. 


\section{Referensi}

[1]. Kirk, B. E. dan Othmer, D.F. Encyclopedia of Chemical Technology, New York. 1985.

[2] Rodrigues, G., Santos, D., Meireles, S., Maria, R., and Assunc, N.De. Carbohydrate Polymers. 2008;73: 74-82.

[3] Cheng, H.N., Dowd, M.K., Selling, G.W., and Biswas, A. Carbohydrate Polymers. 2010;80(2) 449-452.

[4] Fan, G., Wang, M., Liao, C., Fang, T., Li, J., and Zhou, R. Carbohydrate Polymers. 2013;94(1): 71-76.

[5] Widyaningsih, S. dan Radiman, C.L. Jurnal Molekul. 2007;2(1): 13-16.

[6] Anugraini, A., Syahbanu, I., Melati, H.A. Marine bioactivities. Jurnal Kimia Khatulistiwa,2018; $7(3), 18-26$

[7] Dolatowski, O., Petrik, L., Amigun, B., Ameer, F. Energies. 2009;3:1691-1703.

[8] Li, J., Cai, J., Fan, L. Journal of Applied Polymer Science. 2008;109:2417-2425

[9] Taghizadeh, M. T., dan Mehrdad, A. Ultrasonics Sonochemistry. 2003; 10(6) : 309-313.

[10] Li, R., dan Feke, D.L. Food Chemistry. 2015; 172 : 808-813.

[11] Schnabel, W. Polymer Degradation, Principles and Practical Application. Wiley-VCH Verlag GmbH\&Co. KGaA, Weinheim, Muenchen, Jerman. 1981

[12] Gronroos, A., Pentti P., Hanna K. Ultrasonics Sonochemistry. 2008; 15:644-648.

[13] Stuart, B. Polymer Analysis. Wiley-VCH Verlag GmbH\&Co. KGaA, Weinheim, Muenchen, Jerman. 2002

[14] Radiman, C., dan Yuliani, G. PolymerInterntional. 2008;52:54 